\title{
Research on the Probability Theory and Mathematical Statistics Teaching

\author{
Wenyao Xiong
}

Nanchang Institute of Science \& Technology

Keywords: Probability theory; Mathematical statistics; Teaching and research

\begin{abstract}
Probability theory and mathematical statistics is a basic course that various professional departments of undergraduate institutions offer, which does not only cover various aspects but also can be applied in various subjects. Concerning the subject itself, it studies on random phenomenon, which is largely different from previous mathematical sciences in terms of thinking mode and shall be difficult for students to master and understand. This paper starts from the problems and difficulties of university mathematic education, combines the characteristics of probability theory and mathematical statistics as well as current teaching condition to study and discuss about the education reform. What's more, based on the concrete condition of schools, it comes up with some new suggestions which can effectively improve the teaching quality.
\end{abstract}

\section{Introduction}

Probability theory and mathematical statistics is a mathematical science which study on the random phenomenon and rules, with its ideas and methods widely being applied in social practice, scientific experiment, financial economy, chemical engineering and physics etc. Because of the development of scientific technology as well as the accelerating of knowledge updating, traditional concepts and approaches of university education should be changed so as to adapt to the new trend. Then, how to strengthen students' competition consciousness and cultivate their innovation and application ability, how to continually introduce advanced scientific technology, concept and approaches into classes shall be problems for educators to think about. Probability theory and mathematical statistic is deemed as a basic approach for modern engineering, information, society and economic research application, and is a core mathematical subject. Recently, probability and statistics has been applied in many subjects, including finance, earth science, life science, artificial intelligence, and communication network.

How to learn well has become a topic which worths universities as well as all concerned parties to think about it. This paper discusses about the characteristics of probability statistics and the current condition as well as problems of current mathematical education, which also combines some theories of modern educational psychology to discuss about the educational reform of probability statistics.

\section{Problems of Probability Theory Course Teaching}

Nowadays, the information is highly developed and the basic theory as well as approaches of stochastic mathematics have been highlighted in information collection, processing and application and have become necessary standard to value a modern professionals. However, the current education has the following problems:

It emphasizes professional education and therefore there will be partial understanding on the function of university mathematical education, that is to serve the professions, which reflect on each sector of the education as guiding ideas and will exert a huge impact. At present, a dazzling array of teaching staff still have the same understanding because they never study on the function of university mathematics in university education.

For teachers, the teaching contents are dull while the teaching plan and syllabi are fixed, therefore, they are only responsible for textbooks and examination and tend to ignore the cultivation on students' ability and quality, thus affect the full play of enthusiasm and growth. What's more, 
concerning the teaching methods, they highlight the symbolic match and problem-solving skill training, ignoring the guidance from direct (application and aesthetic feeling) and background perspectives. Besides, they teach based on a simplest way without reasoning and students cannot be active.

A same major implement liberal arts and science enrollment and students' mathematical level has a huge gap because they come from different places, which will bring along with difficulties for teachers to organize teaching.

\section{Strengthening Curriculum System}

Teaching contents refer to the information conveyed during the interaction between teachers and students, who complete their learning under the guidance of teachers. So, teachers are of important guidance to carry out a comprehensive teaching plan. We choose proper teaching materials, including basic knowledge for probability theory (random event and probability, random variable and distribution, the numerical characteristics for random variables, law of large numbers and central limit theory) and mathematical statistics (sampling distribution, interval estimation, hypothesis testing). Teachers can introduce statistics ideas and strengthen applications, for example, they can introduce some cases in economics for students to carry out a discussion, which cannot only establish a sound learning environment but also enliven classroom atmosphere and upgrade teaching effect.

During the teaching process of probability theory and mathematical statistics, the following approaches can be adopted:

Expositive teaching: Teachers complete the teaching task mainly based on classroom instruction, including large-span introduction, formula derivation confirmation, problem explanation, content summary, exercise class;

Heuristic teaching: Teachers prepare the teaching content in advance, determine the point cut and process monitoring point and adopt observation, hint, description to guide students to deeply think about the problems with solutions;

Self-study approach: Students think independently, study intensively, practice and apply the knowledge so as to grasp the knowledge and acquire the ability to learn new stuff, which can help them be adapted to the society with rapid development of technology;

Guided discovery style: Under the guidance of teachers, we mobilize students' subjective initiative through self-study, discussion, extensive reading, summary and homework so as to cultivate students' ability to learn by themselves, which demonstrate the principle of students as subject while teachers as guiders;

Comparative teaching method: While teaching, teachers carry out comparison between the new knowledge and old one as well as the concept so as to strengthen understanding and memory.

\section{Introducing Mathematical Modeling}

The basic idea of mathematical modeling is to adopt mathematical knowledge to establish models so as to solve practical problems. Probability theory is an applied mathematical course with a heap of abstract concepts and theoretical knowledge. We can introduce mathematical modeling and concepts, natures as well as theories into real problems, while choosing realistic, applied and operation-oriented case to help students solve the problems with probability statistics knowledge so as to ignite students' enthusiasm and enhance their application ability. Mathematical modeling can enable students to feel and understand the process of knowledge emergence and development, cultivate their scientific and innovative spirit, promote their ability to collect and acquire knowledge, and at the same time improve the ability to analyze and solve problems. For example, to have a second child is a basic state policy of China. If the first child is a girl, the couple can have a second baby yet they cannot have a third baby. So, will this policy exert impact on the proportion of boys and girls? This problem include the probability issue which can be analyzed based on models. We can also introduce the problem into classroom so as to improve students' ability to analyze and 
solve problems.

Good mathematical skills, innovative thinking ability and application ability are requirements for talents in the new century, so probability theory and mathematical statistics is of crucial importance.

\section{Conclusion}

The reform of probability and mathematical statistics reform has achieved a mighty advance and a glittering array of innovative course contents, structures, new schemes for system reform, teaching materials and curriculum have emerged. What's more, to reform the teaching approaches and introduce new research and practice for teaching methods have attracted the attention of various maths teachers. However, the development is not balanced and there is a shortage of systematic and comprehensive experiment. Overall, the traditional teaching method and approaches do not change a lot and it is difficult to update the teaching contents. This paper starts from the problems and difficulties of university mathematic education, combines the characteristics of probability theory and mathematical statistics as well as current teaching condition to study and discuss about the education reform and innovation so as to provide a good learning policy for teachers and students.

\section{References}

[1] Russell A G, Winner D A, Harley R A, et al. Mathematical modeling and control of the dry deposition flux of nitrogen-containing air pollutants [J]. Environmental Science \& Technology, 1993, 27(13):2772-2782.

[2] Harley R A, Russell A G, Cass G R. Mathematical modeling of the concentrations of volatile organic compounds: model performance using a lumped chemical mechanism [J]. Environmental Science \& Technology, 2002, 27(8):1638-1649.

[3] Morgan, J. A., and D. Rhodes. "Mathematical modeling of plant metabolic pathways" Metabolic Engineering 4.1(2002):80-89.

[4] M. G. Slin'ko. History of the development of mathematical modeling of catalytic processes and reactors [J]. Personnel Psychology, 2007, 41(1):13-29.

[5] Cu Y, Saltzman W M. Mathematical modeling of molecular diffusion through mucus. [J]. Advanced Drug Delivery Reviews, 2009, 61(2):101-14.

[6] Chen Y, Halm N P, Groll E A, et al. Mathematical modeling of scroll compressors-part I: compression process modeling [J]. International Journal of Refrigeration, 2002, 25(6):731-750.

[7] Greenberg R S, Kleinbaum D G. Mathematical Modeling Strategies for the Analysis of Epidemiologic Research [J]. Annual Review of Public Health, 1985, 6(1):223-45.

[8] Palumbo P, Ditlevsen S, Bertuzzi A, et al. Mathematical modeling of the glucose-insulin system: A review [J]. Mathematical Biosciences, 2013, 244(2):69-81.

[9] Chaplain M A J, Orme M E. Mathematical Modeling of Tumor-Induced Angiogenesis [M]// Vascular Morphogenesis: In Vivo, In Vitro, In Mente. Birkhäuser Boston, 1996:111-187.

[10]Luce R D. Four tensions concerning mathematical modeling in psychology. [J]. Annual Review of Psychology, 1995, 46(46):1-26.

[11]Botte G G, Subramanian V R, White R E. Mathematical modeling of secondary lithium batteries [J]. Electrochimica Acta, 2000, volume 45(15-16):2595--2609.

[12]Reynolds S D, Roth P M, Seinfeld J H. Mathematical modeling of photochemical air pollution-I : Formulation of the model[J]. Atmospheric Environment, 1973, 7(7):1033-1061. 